\title{
A novel $(\mathrm{TG})_{n}(\mathrm{GA})_{m}$ repeat polymorphism 254 bp downstream of the mast cell chymase (CMA1) gene is associated with atopic asthma and total serum IgE levels
}

Received: 17 February 2005 / Accepted: 23 March 2005 / Published online: 28 May 2005

(C) The Japan Society of Human Genetics and Springer-Verlag 2005

\begin{abstract}
The gene for mast cell chymase (CMA1) is an ideal candidate for investigating genetic predisposition to atopic asthma, as it is an important mediator of inflammation and remodeling in the asthmatic lung. Various studies have examined the association between -1903 G/A polymorphism and allergic phenotypes, but inconsistent results have been obtained. We investigated the association of this SNP and a novel $(\mathrm{TG})_{n}(\mathrm{GA})_{m}$ repeat polymorphism (accession no. BV210164) $254 \mathrm{bp}$ downstream of the gene with asthma and its associated traits in a case-control study in two independent cohorts recruited from the Indian population. A significant association was observed for the $(\mathrm{TG})_{n}(\mathrm{GA})_{m}$ repeat with asthma $(p<0.05)$ in both the cohorts. Although no association was observed for the $-1903 \mathrm{G} / \mathrm{A}$ SNP with asthma, a significant association was observed between the genotypes and serum IgE levels $(p=0.003$ and 0.0004 for cohort A and B). When haplotypes were compared between patients and controls, the haplotype $\mathrm{G}_{-} 43$ was found at higher frequency in controls $(p=0.05)$. Allso, on comparing major haplotypes ( $>5 \%$ ) with respect to $\log$ total serum IgE levels, a significant difference was obtained ( $p=0.018$ and $p=0.046$ for cohorts $\mathrm{A}$ and $\mathrm{B}$ ). These results suggest that the $C M A 1$ gene contributes to asthma susceptibility and may be involved in regulating $\operatorname{IgE}$ levels in atopic asthma.
\end{abstract}

Keywords Atopic asthma $C M A 1 \cdot$ Serum IgE . $(\mathrm{TG})_{n}(\mathrm{GA})_{m}$ repeat polymorphism

\footnotetext{
S. Sharma · U. M. Rajan · A. Kumar · A. Soni · B. Ghosh $(\bowtie)$ Molecular Immunogenetics laboratory,

Institute of Genomics and Integrative Biology,

Mall Road, Delhi 110007, India

E-mail: bghosh@igib.res.in

Tel.: +91-11-27662580

Fax: +91-11-27667471
}

\section{Introduction}

Asthma is a complex airway disorder affecting 15-18\% of the world's population, with both environmental and genetic factors playing key roles. Atopic asthma accounts for up to $11-12 \%$ of the Indian population (Ghosh et al. 2003; Smith 2000). Clinically, asthma is presented as a reversible obstruction of bronchi, usually associated with high levels of total serum IgE (Geha et al. 2003). Mast cells have been implicated in many pathological features of chronic asthma (Hart 2001; Marshall 2004). These are a rich source of potent inflammatory mediators such as histamine, leukotrienes, and the serine proteases tryptase and chymase, which have been shown to have various roles in tissue remodeling and cellular recruitment (Lazaar et al. 2002; Marshall 2004). Apart from these mediators, mast cells are an important source of various proinflammatory cytokines and chemokines, such as IL-4, IL-5, IL-13, CC-chemokine ligand 5 (CCL5), etc., and thus play a key role in the initiation of allergic response (Marshall 2004).

Mast cell chymase (CMA1) is a chymotrypsin-like protease stored in high amounts within the secretory granules of mast cells found in asthmatic airway (Hart 2001). After release from the activated mast cells, CMA1 has a range of proinflammatory effects in cooperation with histamine (He et al. 2004; Tomimori et al. 2002). It has been shown to activate several biological mediators, including angiotensin I, IL-1 $\beta$, and endothelin-1, by the cleavage of precursor forms of these molecules (Lazaar et al. 2002). Injection of the human form of the enzyme into rodent models leads to increased microvascular permeability and accumulation of eosinophils and neutrophils (He and Wall 1998a, 1998b). Previous studies have suggested that chymase has profound effects on airway smooth muscle cell functioning and contributes to airway remodeling, an established pathological feature in asthma, by initiating the formation of collagen fibrils from type I procollagen and causing the activation 
of inactive enzymes, including pro-MMP-1 (promatrix metalloproteinase-1) and interstitial procollagenase. Apart from this, CMA1 also induces the release of TGF$\beta$ through the activation of MMP-9 (matrix metalloproteinase-9) secreted in bronchoalveolar lavage (BAL) fluid of asthmatics in response to inflammatory cytokines (Lazaar et al. 2002). The released TGF- $\beta$, in turn, stimulates the formation of connective tissue and thereby promotes fibrosis in areas of injury (Duvernelle et al. 2003). The accumulation of low-molecular-weight matrix constituents following chymase action results in further profibrotic stimuli (Lazaar et al. 2002). On the other hand, chymase may indirectly serve to limit some of the pathological features in chronic inflammatory diseases. For example, previous studies have shown that chymase inhibits the expression of collagen and vascular smooth muscle proliferation in the fibrous caps of advanced atherosclerotic lesions (Wang et al. 2001). In addition, it also induces the apoptosis of vascular smooth muscle cells in such lesions (Leskinen et al. 2001). Thus, CMA1 can play a proinflammatory as well as an anti-inflammatory role depending on the context.

The gene for CMA1 is located within a cluster of genes for cellular proteases on chromosome $14 \mathrm{q} 11.2$ (Caughey et al. 1993). Previous studies have identified the genes for cathepsin-G, cathepsin-G-like protein, CGL2, and CMA1 as potential candidate genes for asthma in this region (CSGA 1997). Studies carried out in the Japanese population have reported an association between atopic dermatitis/eczema and $-1903 \mathrm{G} / \mathrm{A}$ polymorphism (rs1800875) in the CMA1 gene (Mao et al. 1996, 1998; Tanaka et al. 1999). On the other hand, a recent study in the Caucasian population found no significant association between genotypes at this locus and asthma; however, a significant association was found between genotypes and total IgE levels in subjects with self-reported eczema (Iwanaga et al. 2004).

The aim of the present study was to detect genetic variants of CMAI in the Indian population and to evaluate the association between these markers individually and at the level of genotype and haplotype to asthma status and the quantitative traits associated with asthma, such as total serum $\operatorname{IgE}$ levels, using a wellcharacterized case control study design in two independent cohorts recruited from the Indian population.

\section{Materials and methods}

\section{Subjects}

Unrelated asthma patients were recruited from various collaborating hospitals of northern India in cohort A $(n=188)$ and western India in cohort B $(n=207)(\mathrm{Ta}-$ ble 1). The ethical committees of the participating centers and hospitals approved the study. Written informed consent was obtained from all individuals participating in the study. Asthma, in the recruited study population was defined by clinical history and validated later by interview questions (details of environmental factors, family history of asthma/atopy, and the geographical region of origin and migration status). Patients (mean ages $28.42 \pm 0.97$ and $34.22 \pm 1.01$ years for cohort A and $\mathrm{B}$, respectively) were diagnosed for asthma on the basis of National Asthma Education and Prevention Program (Expert Panel Report-2) guidelines (Nagpal et al. 2005) and were examined for a self-reported history of breathlessness and wheezing. The clinical parameters are summarized in Table 1. Each patient showed airway reversibility as documented by an inhalant-bronchodilator-induced improvement of more than $15 \%$ (using albuterol/salbutamol). Fifteen common environmental allergens were used for the skin prick test (SPT). Atopy was defined as having wheal reaction equal to or greater than histamine ( $3 \mathrm{~mm}$ diameter). All asthmatic subjects were positive to at least one antigen used for SPT. Total serum IgE levels were estimated for all individuals, except a few individuals $(<10 \%)$ where sera were not available, using ELISA (Nagpal et al. 2005). Only individuals with a family history of asthma/ atopy were included in the study.

Healthy volunteers (referred to as normal controls) ( $n=191$ and $n=174$ in cohorts A and B, respectively) were recruited on the basis of the criteria of having no

Table 1 Demographic profile of the patient and the control groups. Parenthesis contains the values for standard error (SE). ND test not done

\begin{tabular}{|c|c|c|c|c|}
\hline & \multicolumn{2}{|l|}{ Patients } & \multicolumn{2}{|l|}{ Controls } \\
\hline Mean age & $28.42( \pm 0.97)$ & 34.22 years $( \pm 1.01)$ & 24.01 years $( \pm 0.95)$ & 29.35 years $( \pm 1.00)$ \\
\hline Sex ratio $(M: F)$ & $0.52: 0.48$ & $0.54: 0.46$ & $0.58: 0.42$ & $0.56: 0.44$ \\
\hline Familial history of asthma/atopy & All & All & None & None \\
\hline Smoking history & None & None & None & None \\
\hline Log mean total serum IgE (IU/ml) & $2.84 \pm 0.08$ & $2.87 \pm 0.04$ & $2.40 \pm 0.07$ & $2.37 \pm 0.05$ \\
\hline Self-reported history of allergies & All & All & None & None \\
\hline
\end{tabular}

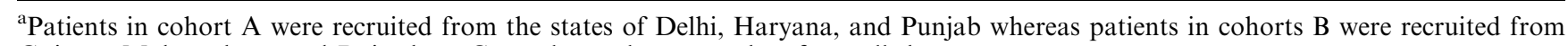
Gujarat, Maharashtra, and Rajasthan. Control samples were taken from all these states 
symptoms or history of allergic diseases. Individuals having a history of smoking and parasitic/helminthic infestations in the past were excluded from the study. All control individuals recruited for the study were screened negative for all the allergens used for SPT. Total serum IgE levels were determined for all the control samples recruited for the study; however, pulmonary function test (PFT) and SPT were performed wherever consent was obtained (FEV1 >90\%). Individuals who experienced active smoking in the past 3 years or who were suffering from parasitic/helminthic infestations (as determined from the clinical histories) were excluded from the study.

In this study, as the samples were collected from individuals on the basis of their family history, origin, and migration status, the error due to stratification is presumably minimized (Table 1). Indeed, we established the genetic homogeneity between the two groups by genotyping multiple loci as yet unlinked to asthma or related atopic disorders (Sharma et al. 2004). Also, all individuals were age and gender matched (Table 1).

\section{PCR amplification and genotyping}

Genomic DNA was extracted from the peripheral blood leukocytes using the modified salting out procedure, as described (Nagpal et al. 2005). The $-1903 \mathrm{G} / \mathrm{A}$ polymorphism was investigated using primer pairs: 5'-GGAAATGTGAGCAGATAGCGCAGTC- ${ }^{\prime}$ ' and 5'-AATCCGGAGCTGGAGAACTCTTGTC-3'. Polymerase chain reaction (PCR) amplifications were performed in a final volume of $20 \mu \mathrm{l}$ containing $0.1 \mu \mathrm{M}$ concentration of each primer, $1.5 \mathrm{mM} \mathrm{MgCl} 2,200 \mu \mathrm{M}$ dNTPs, 50 ng DNA template and $0.03 \mathrm{U} / \mu \mathrm{l}$ Taq DNA polymerase, and 1XPCR buffer (as recommended by the supplier) (Bangalore Genie, India). Amplified DNA fragments were genotyped by restriction digestion with Bst XI (1 U/15 $\mu$ l reaction, New England Biolabs, Beverly, MA, USA), as per the manufacturer's instructions. PCR products from individuals with GG genotypes were refractory to digestion with BstXI while DNA from homozygotes for the A allele (AA genotype) was completely digested into two fragments. The accuracy of the RFLP genotyping was confirmed by direct sequencing of the DNA samples $(n=20)$ for all three respective genotypes.

Putative repetitive sequences in and around the CMA1 gene (NT_026437) were identified using the RepeatMasker software (http://ftp.genome.washington.edu/RM/ RepeatMasker.html). A novel (TG) ${ }_{n}(\mathrm{GA})_{m}$ repeat (Accession no. BV210164) 254 bp downstream of the gene was validated for distribution in the study population. PCR was carried out in a total volume of $15 \mu l$ containing 25 ng of genomic DNA, 4 pmol each of a 6-FAM-labeled forward primer (5'-ACAACCCTAAGCCTCCAGAAGTAT-3'), and a nonlabeled reverse primer (5'TGATGATTAAGGCAAAGAAGGAT-3'), $\quad 1.5 \mathrm{mM}$ $\mathrm{MgCl}_{2}, 0.25 \mathrm{mM}$ of each dNTP, $0.03 \mathrm{U} / \mu \mathrm{l}$ of Taq DNA polymerase (Bangalore Genie, India), and the buffer recommended by the supplier. Fragment lengths were determined using the GeneMapper ver 3.5 (Applied Biosystems, Foster City, CA, USA). The number of repeats was determined by sequencing the PCR fragments from individuals $(n=5)$ being homozygous for one allele.

\section{Statistical methods}

Kolmogorov-Smirnov (KS) test was used to test the association of the microsatellite allele size distribution with disease (Sharma and Ghosh 2004). Likelihood ratio chi-square test was used to test the genotypic and allelic association of the polymorphisms with asthma (http:// home.clara.net/sisa/). Hardy-Weinberg equilibrium (HWE) for patients as well as controls was calculated using De Finetti program (http://ihg.gsf.de/cgi-bin/hw/ hwa1.pl). Odds ratios (OR) were calculated for the alleles and genotypes. ANOVA was used to assess the significance of association between polymorphisms of the CMAl gene and quantitative phenotypes such as total serum IgE levels. Haplotypes were generated in the patients and the unrelated controls using PHASE version 2.1, which uses a Bayesian approach incorporating a priori expectations of haplotypic structure from population genetic and coalescent theory (Stephens and Donnelly 2003). No missing data were allowed. The association of haplotypes was tested with asthma status and total serum IgE levels. ORs were calculated for haplotypes in which distribution was significantly different in the two groups studied.

\section{Results}

Total serum IgE levels in patients and healthy volunteers

Total serum IgE levels were found to follow a log normal distribution in both the cohorts. When the cases and controls were compared with respect to the log total serum IgE levels, a highly significant difference was obtained (for cohort A: $t$ test $=4.07$, d.f. $=231$, $p<0.0001$ and for cohort B: $t$ test $=7.28$, d.f. $=261$, $p<0.0001)$. There was no significant difference between the cases and the control groups with respect to the age or male-to-female ratio (Table 1).

Association analysis with asthma and total serum IgE levels

For the $-1903 \mathrm{G} / \mathrm{A} \mathrm{SNP}$, the distribution of $C M A 1^{*} \mathrm{~A}$ and $\mathrm{G}$ alleles were not found to be significantly different between the cases and the controls in both cohort A (LR $\chi^{2}=1.49$, d.f. $\left.=1, p=0.22\right)$ and cohort B $\left(\right.$ LR $\chi^{2}=2.89$, d.f. $=1, p=0.089$ ). Also, the distribution of the AA, AG, or GG genotypes was concordant in the cases and the controls for both cohorts $\left(\operatorname{LR} \chi^{2}=2.98\right.$, d.f. $=2, p=0.23$ 
for cohort A and $\mathrm{LR} \chi^{2}=3.41$, d.f. $=2, p=0.18$ for cohort B) (Table 2). The distribution of genotype frequencies of this SNP was consistent with Hardy-Weinberg expectations in the controls for both cohorts $(p>0.05)$. One-way ANOVA showed a significant association between the genotypes for this locus and serum IgE levels $(F$ ratio $=6.12$, d.f. $=2, p=0.003$ for cohort $\mathrm{A}$ and $F$ ratio $=8.55$, d.f. $=2, p=0.0004$ for cohort B) $($ Table 2$)$.

We have identified a novel $(\mathrm{TG})_{n}(\mathrm{GA})_{m}$ repeat (accession no. BV210164) 254 bp downstream of the $C M A$ lgene and used it for genotyping patients and controls in both the cohorts. A total of ten alleles were observed. The frequency distribution of the alleles is represented in Fig. 1. A significant difference was obtained in the allele count in patients and controls $\left(\mathrm{KS} \chi^{2}=7.18\right.$, d.f. $=9, p=0.028$ for cohort $\mathrm{A}$ and $\mathrm{KS} \chi^{2}$ $=7.46$, d.f. $=9, p=0.024$ for cohort B). The heterozygosity index for this repeat polymorphism was 0.76 . The largest difference in allele counts was observed for allele 43 , which was represented in higher frequency in the controls compared with the patients $\left(\mathrm{LR} \chi^{2}=7.09\right.$, d.f. $=1, p=0.008$ for cohort A and LR $\chi^{2}=4.47$, d.f. $=1$, $p=0.03$ for cohort $\mathrm{B})$. The odds ratio for patients having 43 allele rather than any other allele (non-43) compared with controls was 0.59 with Wald's $95 \% \mathrm{CI}=(0.40,0.87)$ for cohort A and 0.68 with Wald's $95 \% \mathrm{CI}=(0.48,0.97)$ for cohort B. One-way ANOVA showed a significant association between the alleles for this locus and serum IgE levels $(F$ ratio $=2.10$, d.f. $=9, p=0.03$ for cohort A and $F$ ratio $=2.25$, d.f. $=8, p=0.026$ for cohort $\mathrm{B}$ ) (Table 3). Hence, the novel $(\mathrm{TG})_{n}(\mathrm{GA})_{m}$ repeat in the $C M A l$ gene is associated with asthma and its associated quantitative trait serum IgE.

Association of CMA1 haplotypes with asthma and total serum IgE levels

To investigate the association of $-1903 \mathrm{G} / \mathrm{A}$ SNP and the novel $(\mathrm{TG})_{n}(\mathrm{GA})_{m}$ repeat at the level of haplotypes, PHASE was used to generate haplotypes for the patient and control samples. Default parameters were used to generate these haplotypes, and the differences in fre-

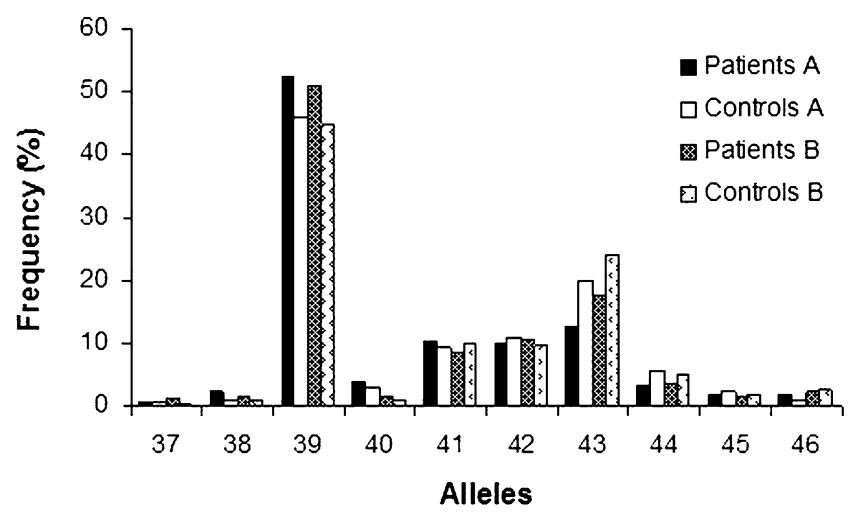

Fig. 1 The frequency distribution of the $(\mathrm{TG})_{n}(\mathrm{GA})_{m}$ repeat $254 \mathrm{bp}$ downstream of the CMAI gene in patients and unrelated controls in cohorts $\mathrm{A}$ and $\mathrm{B}$. The repeat alleles were plotted on the $X$ axis and their respective relative frequencies (\%) on the $Y$ axis

quencies were compared in the two groups. Individuals in both cohorts ( $n=4$ in cases and $n=5$ in controls) with phase probabilities less than $80 \%$ were excluded from the analysis. The 20 haplotypes obtained in the analysis are shown in Fig. 2. The haplotype G_43 was found at a higher frequency in controls in both cohorts $[\mathrm{OR}=0.69$, $95 \% \mathrm{CI}=(0.48,0.99), p=0.045$ for cohort $\mathrm{A}$ and $\mathrm{OR}=0.56,95 \% \mathrm{CI}=(0.37,0.84), p=0.004$ for cohort B]. On comparing the major haplotypes (frequency $>5 \%$ ) with respect to the $\log$ total serum IgE levels, a significant difference was obtained $(F$ ratio $=2.58$, d.f. $=6, p=0.018$ for cohort $\mathrm{A}$ and $F$ ratio $=2.16$, d.f. $=6, p=0.046$ for cohort B). The log total IgE levels corresponding to the respective haplotypes are given in Table 3. Thus, the haplotypes observed in the CMA1 gene are associated with asthma and total serum IgE.

\section{Discussion}

As is widely accepted, mast cell inflammatory mediators play a key role in the initiation and progression of allergic immune responses. Particularly, mast cell tryp-

Table 2 Allele and genotype frequencies for polymorphisms studied in CMA1 gene. IgE values are given as mean \pm SD. Numbers in parentheses indicate the frequency $(\%)$

\begin{tabular}{|c|c|c|c|c|c|c|}
\hline \multirow[t]{3}{*}{$-1903 \mathrm{G} / \mathrm{A}$} & \multicolumn{6}{|c|}{ Number (\%) } \\
\hline & \multicolumn{3}{|l|}{ Cohort A } & \multicolumn{3}{|l|}{ Cohort B } \\
\hline & Patients & Controls & Mean $\log$ total $\operatorname{IgE}(\mathrm{IU} / \mathrm{ml})^{\mathrm{a}}$ & Patients & Controls & Mean log total $\operatorname{IgE}(\mathrm{IU} / \mathrm{ml})^{\mathrm{b}}$ \\
\hline \multicolumn{7}{|l|}{ Alleles } \\
\hline A & $183(48.67)$ & 169 (44.24) & - & $194(49.24)$ & 147 (42.98) & - \\
\hline G & $193(51.33)$ & $213(55.76)$ & - & $200(50.76)$ & $195(57.02)$ & - \\
\hline \multicolumn{7}{|l|}{ Genotypes } \\
\hline AA & $47(25.00)$ & $34(17.80)$ & $2.95 \pm 0.11(56)$ & $45(22.84)$ & $27(15.79)$ & $2.61 \pm 0.13(32)$ \\
\hline $\mathrm{AG}$ & $89(47.34)$ & $101(52.88)$ & $2.63 \pm 0.08(96)$ & $104(52.79)$ & $93(54.39)$ & $2.21 \pm 0.07(126)$ \\
\hline GG & $52(27.66)$ & $56(29.32)$ & $3.01 \pm 0.12$ & $48(24.37)$ & $51(29.82)$ & $2.67 \pm 0.11(50)$ \\
\hline
\end{tabular}

${ }^{\mathrm{a}} F$ ratio $=6.12$, d.f. $=2, p=0.003$

${ }^{\mathrm{b}} F$ ratio $=8.55$, d.f. $=2, p=0.0004$ 
Fig. 2 Frequency distribution of the two-locus haplotypes of the CMAl gene in patients and unrelated controls in cohorts A and $\mathrm{B}$. The haplotypes were plotted on the $X$ axis and their respective relative frequencies $(\%)$ on the $Y$ axis

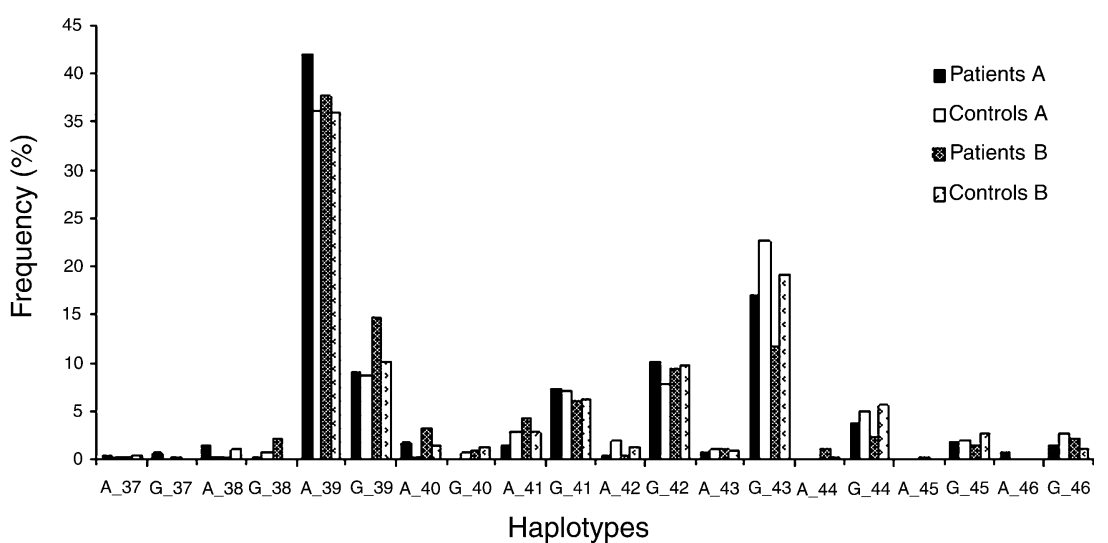

Table 3 Mean log total serum IgE values in individuals according to allele/haplotype. IgE values are given as mean \pm SD. Numbers in parenthesis indicate the number of chromosomes used for analysis

\begin{tabular}{|c|c|c|c|c|c|}
\hline$(\mathrm{TG})_{n}(\mathrm{GA})_{m}$ repeat allele & \multicolumn{2}{|c|}{ Mean $\log$ total $\mathrm{IgE}$ values $(\mathrm{IU} / \mathrm{ml})$} & Haplotype & \multicolumn{2}{|c|}{ Mean $\log$ total $\mathrm{IgE}$ values $(\mathrm{IU} / \mathrm{ml})$} \\
\hline 38 & $3.12 \pm 0.57(2)$ & $2.43 \pm 0.31(3)$ & $\mathrm{A}^{-} 41$ & $2.17 \pm 0.19$ & $2.17 \pm 0.27$ \\
\hline 39 & $2.30 \pm 0.07(127)$ & $2.33 \pm 0.06(93)$ & $\mathrm{G}_{-}^{-} 39$ & $2.38 \pm 0.10(46)$ & $2.66 \pm 0.07(45)$ \\
\hline 40 & $3.40 \pm 0.31(7)$ & $2.58 \pm 0.31(3)$ & $\mathrm{G}_{-}^{-} 41$ & $2.60 \pm 0.14(25)$ & $2.80 \pm 0.09(29)$ \\
\hline 41 & $2.47 \pm 0.16$ & $2.03 \pm 0.13(18)$ & $\mathrm{G}^{-} 42$ & $2.73 \pm 0.13(27)$ & $2.68 \pm 0.09(26)$ \\
\hline 44 & $2.72 \pm 0.29(8)$ & $2.92 \pm 0.19(8)$ & & & \\
\hline 45 & $2.73 \pm 0.33(6)$ & $1.97 \pm 0.38(2)$ & & & \\
\hline 46 & $2.47 \pm 0.57(2)$ & $2.25 \pm 0.22(6)$ & & & \\
\hline
\end{tabular}

tase and chymase are key players in mediating chronic inflammation, as observed in the lungs of asthmatics, thus marking them as potential candidate genes to be studied in asthma and atopy (Hart 2001).

In the present study, a known polymorphism, namely $-1903 \mathrm{G} / \mathrm{A}$ SNP, was screened in the Indian population, and no significant association was found with asthma. Previously, a significant association has been observed between atopic dermatitis and this polymorphism in three independent studies carried out in the Japanese population (Mao et al. 1996, 1998; Tanaka et al. 1999). On the other hand, other studies carried out with atopic dermatitis or with asthma in the Japanese, Australian, Italian, and Caucasian populations failed to replicate these findings (Forrest et al. 1999; Iwanaga et al. 2004; Kawashima et al. 1998; Pascale et al. 2001). The differences in results from these studies carried out in different populations could be attributed to variation on phenotype definitions, ethnicity, and environmental exposure. Furthermore, the studies showing positive association were carried out with samples from atopic dermatitis patients and not from atopic asthmatics. With reference to this, we used samples from atopic asthmatic individuals in our study.
Interestingly, however, we observed a significant association between the genotypes for the $-1903 \mathrm{G} / \mathrm{A}$ SNP and total serum IgE. The study carried out in the Caucasian population reported a similar association with total serum IgE, wherein the GG genotype was associated with highest IgE levels, followed by GA heterozygotes while the AA homozygotes had the lowest IgE levels (Iwanaga et al. 2004). However, in the cohorts used for our study, the GG homozygotes had the highest IgE levels, followed by AA homozygotes whereas the GA heterozygotes had the lowest IgE levels. The apparent reason(s) for this observation is not clear at the moment. In any event, as IgE levels are controlled by many genes, it is possible that some other linked/unlinked loci is contributing to the high IgE levels associated with GG homozygotes. It is also important to note here that the patients used for our study were atopic asthmatics only whereas the patients used in the Caucasian study had self-reported eczema along with asthma (Iwanaga et al. 2004). Thus, the difference in the results may also be attributed to the differences in subjects used in the two studies, apart from the ethnicity and environmental exposure. Interestingly, the study in the Caucasian population also failed to find any association 
for this polymorphism with asthma, thus supporting our results. Therefore, this SNP, although it might not be associated with asthma, could be regulating some aspects of total IgE levels in atopic disorders.

In the present study, we identified and genotyped a novel complex $(\mathrm{TG})_{n}(\mathrm{GA})_{m}$ repeat 254 bp downstream of the CMAlgene and examined the association of this polymorphism with asthma and serum IgE levels. Both the (TG) $)_{n}$ and the $(\mathrm{GT})_{m}$ stretch were polymorphic, as was confirmed by sequencing. However, the allele size was calculated on the basis of total repeat length. Importantly, using the $(\mathrm{TG})_{n}(\mathrm{GA})_{m}$ repeat, our study showed for the first time a positive association for this gene with asthma as well as with serum $\operatorname{IgE}$ levels. Though no functional role has as yet been assigned for this repeat, it may be controlling the expression/activity of CMA1, as has been shown by earlier studies that dinucleotide repeats are involved in gene regulation and are associated with various complex genetic disorders. For example, a short tandem repeat termed MNS16A downstream of the human telomerase gene is known to control its expression and hence involved in predicting susceptibility to develop lung cancer (Wang et al. 2003). Alternatively, it cannot be excluded that the association observed could be due to another causal allele in linkage disequilibrium with the complex repeat studied here.

To further the understanding of the contributions of this gene toward asthma, we constructed haplotypes using PHASE (Stephens and Donnelly 2003). The overall distribution of the different haplotypic combinations was significantly different in patients and controls. In addition, we identified a major haplotype, G_43, in the controls, marking it as a protective haplotype for asthma. It is important to note here that the distribution of the 43 allele for the (TG) ${ }_{n}(\mathrm{GA})_{m}$ repeat was almost similar to the haplotype G_43. However, this finding is not surprising, as these two loci are in strong LD with each other $\left(D^{\prime}=0.91\right.$ and $D^{\prime}=0.88$ for controls in cohort A and B, respectively). This suggests that the combined effect of both the loci taken together is similar to the repeat allele alone and that the $(\mathrm{TG})_{n}(\mathrm{GA})_{m}$ repeat may be playing a bigger role compared with the SNP. It would also be interesting to address the contribution of the nature of this repeat in addition to the length of the repeat in the future.

The functional consequences of the association of CMA1 genotypes and haplotypes and their association with total $\operatorname{IgE}$ levels in subjects with asthma is rather speculative in terms of the known actions of human chymase. The protease may have a role in controlling the bioavailability of several cytokines, being able to degrade IL-4 (Tunon de Lara et al. 1994), convert IL-1 into the active form (Mizutani et al. 1991), and the release of a membrane-bound form of stem cell factor (Longley et al. 1997). Murine spleen cells stimulated with IL-4 and lipopolysaccharide have been shown in in vitro experiments to enhance the synthesis of $\operatorname{IgE}$ on addition of a rat chymase (rat mast cell protease I) (Yoshikawa et al. 2001). Suppression of total serum IgE levels was also observed when a synthetic CMA1 inhibitor (Y-40613) was administered to a rat model of atopic dermatitis (Imada et al. 2002).

As asthma is a complex disorder, we used a wellcharacterized (age- and gender-matched) case-control study to find a promising locus associated with it (Sharma et al. 2004). However, to eliminate the chance of a false positive finding, we established the genetic homogeneity between patients and controls by genotyping markers as yet unlinked to asthma (Sharma et al. 2004). Moreover, the validation of our results in another independent cohort could only add more confidence to our results. These leads can be further tested using a well-controlled family-based study.

To summarize, we report here the association of $(\mathrm{TG})_{n}(\mathrm{GA})_{m}$ repeat polymorphism in the CMAl gene with asthma. The findings of the present study suggest that the alleles/haplotypes investigated in the CMAI gene or a functional variant in LD with them are important determinants of asthma susceptibility. Moreover, it would be interesting to investigate the polymorphisms in the genes involved in the biosynthesis of mediators such as leukotrienes ( $\mathrm{LTD}_{4}$ and $\mathrm{LTC}_{4}$ ), prostaglandins $\left(\mathrm{PGD}_{2}\right)$, and tryptase or in the pathways leading to the generation of these mediators (both IgE and FceRI dependent and independent). We recently reported a strong association between asthma and the polymorphisms of $\mathrm{Fc} \epsilon \mathrm{RI} \beta$, an important component of Fc $\epsilon$ RI receptor-mediated signal transduction upon receptor crosslinking with $\mathrm{IgE}$, in two independent cohorts from the Indian population (Sharma et al. 2004). Therefore, it would be interesting to investigate the gene-gene interactions for various important genes involved in mast cell degranulation and study their combined effects on the initiation and progression of asthma.

Acknowledgements We thank our collaborating physicians Drs. S.K. Sharma, Brajen Lahker, Aditi Sinha, Virender Kumar, N.K. Bhatia and P.V. Niphadkar for helping us in sample collection. We also thank all patients, their family members, and healthy volunteers for participating in this study. We thank Ms. Mamta Sharma, Ms. Jyotsna Batra, Mr. Rajshekhar Chatterjee, Ms. Deepti Mann, Ms. Sanober Nahid, and Ms. Sangeeta Goswami for assistance. We acknowledge the Functional Genomics Unit of IGIB, Delhi, for helping in sequencing and genotyping. The financial support from the Council of Scientific and Industrial Research (CSIR), Government of India, is greatly acknowledged.

\section{References}

Caughey GH, Schaumberg TH, Zerweck EH, Butterfield JH, Hanson RD, Silverman GA, Ley TJ (1993) The human mast cell chymase gene (CMA1): mapping to the cathepsin G/granzyme gene cluster and lineage-restricted expression. Genomics 15:614-620

CSGA (1997) [No authors listed] A genome-wide search for asthma susceptibility loci in ethnically diversepopulations. The Collaborative Study on the Genetics of Asthma. Nat Genet 15(4):389-392

Duvernelle C, Freund V, Frossard N (2003) Transforming growth factor-beta and its role in asthma. Pulm Pharmacol Ther $16: 181-196$ 
Forrest S, Dunn K, Elliott K, Fitzpatrick E, Fullerton J, McCarthy M, Brown J, Hill D, Williamson R (1999) Identifying genes predisposing to atopic eczema. J Allergy Clin Immunol 104:1066-1070

Geha RS, Jabara HH, Brodeur SR (2003) The regulation of immunoglobulin E class-switch recombination. Nat Rev Immunol 3:721-732

Ghosh B, Sharma S, Nagarkatti R (2003) Genetics of asthma: current research paving the way for development of personalized drugs. Indian J Med Res 117:185-197

Hart PH (2001) Regulation of the inflammatory response in asthma by mast cell products. Immunol Cell Biol 79:149-153

He S, Walls AF (1998a) Human mast cell chymase induces the accumulation of neutrophils, eosinophils and other inflammatory cells in vivo. Br J Pharmacol 125:1491-1500

He S, Walls AF (1998b) The induction of a prolonged increase in microvascular permeability by human mast cell chymase. Eur $\mathbf{J}$ Pharmacol 352:91-98

He SH, Xie H, Zhang XJ, Wang XJ (2004) Inhibition of histamine release from human mast cells by natural chymase inhibitors. Acta Pharmacol Sin 25:822-826

Imada T, Komorita N, Kobayashi F, Naito K, Yoshikawa T, Miyazaki M, Nakamura N, Kondo T (2002) Therapeutic potential of a specific chymase inhibitor in atopic dermatitis. Jpn J Pharmacol 90:214-217

Iwanaga T, McEuen A, Walls AF, Clough JB, Keith TP, Rorke S, Barton SJ, Holgate ST, Holloway JW (2004) Polymorphism of the mast cell chymase gene (CMA1) promoter region: lack of association with asthma but association with serum total immunoglobulin E levels in adult atopic dermatitis. Clin Exp Allergy 34:1037-1042

Kawashima T, Noguchi E, Arinami T, Kobayashi K, Otsuka F, Hamaguchi H (1998) No evidence for an association between a variant of the mast cell chymase gene and atopic dermatitis based on case-control and haplotype-relative-risk analyses. Hum Hered 48:271-274

Lazaar AL, Plotnick MI, Kucich U, Crichton I, Lotfi S, Das SK, Kane S, Rosenbloom J, Panettieri RA Jr, Schechter NM, Pure E (2002) Mast cell chymase modifies cell-matrix interactions and inhibits mitogen-induced proliferation of human airway smooth muscle cells. J Immunol 169:1014-1020

Leskinen M, Wang Y, Leszczynski D, Lindstedt KA, Kovanen PT (2001) Mast cell chymase induces apoptosis of vascular smooth muscle cells. Arterioscler Thromb Vasc Biol 21:516-522

Longley BJ, Tyrrell L, Ma Y, Williams DA, Halaban R, Langley K, Lu HS, Schechter NM (1997) Chymase cleavage of stem cell factor yields a bioactive, soluble product. Proc Natl Acad Sci USA 94:9017-9021

Mao XQ, Shirakawa T, Yoshikawa T, Yoshikawa K, Kawai M, Sasaki S, Enomoto T, Hashimoto T, Furuyama J, Hopkin JM, Morimoto K (1996) Association between genetic variants of mast-cell chymase and eczema. Lancet 348:581-583

Mao XQ, Shirakawa T, Enomoto T, Shimazu S, Dake Y, Kitano H, Hagihara A, Hopkin JM (1998) Association between variants of mast cell chymase gene and serum IgE levels in eczema. Hum Hered 48:38-41
Marshall JS (2004) Mast-cell responses to pathogens. Nat Rev Immunol 4:787-799

Mizutani H, Schechter N, Lazarus G, Black RA, Kupper TS (1991) Rapid and specific conversion of precursor interleukin 1 beta (IL-1 beta) to an active IL-1 species by human mast cell chymase. J Exp Med 174:821-825

Nagpal K, Sharma S, B-Rao C, Nahid S, Niphadkar PV, Sharma SK, Ghosh B (2005) TGF 1 haplotypes and asthma in Indian population. J Allergy Clin Immunol 115:527-533

Pascale E, Tarani L, Meglio P, Businco L, Battiloro E, CiminoReale G, Verna R, D’Ambrosio E (2001) Absence of association between a variant of the mast cell chymase gene and atopic dermatitis in an Italian population. Hum Hered 51:177-179

Sharma S, Ghosh B (2004) Association of an intragenic microsatellite marker in $\mathrm{CC} 16$ gene with asthma in Indian population. J Hum Genet 49:677-683

Sharma S, Nagarkatti R, B-Rao C, Niphadkar PV, Vijayan V, Sharma SK, Ghosh B (2004) A_16_C haplotype in the FcepsilonRIbeta gene confers a higher risk for atopic asthma in the Indian population. Clin Genet 66:417-425

Smith KR (2000) Inaugural article: national burden of disease in India from indoor air pollution. Proc Natl Acad Sci USA 97:13286-13293

Stephens M, Donnelly P (2003) A comparison of bayesian methods for haplotype reconstruction from population genotype data. Am J Hum Genet 73:1162-1169

Tanaka K, Sugiura H, Uehara M, Sato H, Hashimoto-Tamaoki T, Furuyama J (1999) Association between mast cell chymase genotype and atopic eczema: comparison between patients with atopic eczema alone and those with atopic eczema and atopic respiratory disease. Clin Exp Allergy 29:800-803

Tomimori Y, Tsuruoka N, Fukami H, Saito K, Horikawa C, Saito M, Muto T, Sugiura N, Yamashiro K, Sumida M, Kakutani S, Fukuda Y (2002) Role of mast cell chymase in allergen-induced biphasic skin reaction. Biochem Pharmacol 64:1187-1193

Tunon de Lara JM, Okayama Y, McEuen AR, Heusser $\mathrm{CH}$, Church MK, Walls AF (1994) Release and inactivation of interleukin-4 by mast cells. Ann NY Acad Sci 725:50-58

Wang Y, Shiota N, Leskinen MJ, Lindstedt KA, Kovanen PT (2001) Mast cell chymase inhibits smooth muscle cell growth and collagen expression in vitro: transforming growth factorbeta1-dependent and -independent effects. Arterioscler Thromb Vasc Biol 21:1928-1933

Wang L, Soria JC, Chang YS, Lee HY, Wei Q, Mao L (2003) Association of a functional tandem repeats in the downstream of human telomerase gene and lung cancer. Oncogene 22:71237129

Yoshikawa T, Imada T, Nakakubo H, Nakamura N, Naito K (2001) Rat mast cell protease-I enhances immunoglobulin $\mathrm{E}$ production by mouse B cells stimulated with interleukin-4. Immunology 104:333-340 